\title{
SOME ASPECTS OF THE ORIENTATION OF GALAXIES IN CLUSTERS*
}

\author{
P. Pajowska ${ }^{1}$, W. Godłowski ${ }^{2}$, E. Panko ${ }^{3}$, P. Flin ${ }^{4}$ \\ ${ }^{1}$ Uniwersytet Opolski, Institute of Physics, ul. Oleska, 48, \\ 45-052 Opole, Poland, e-mail: paoletta@interia.pl, \\ ${ }^{2}$ Uniwersytet Opolski, Institute of Physics, \\ ul. Oleska, 48, 45-052 Opole, Poland, e-mail: godlowski@uni.opole.pl, \\ ${ }^{3}$ Kalinenkov Astronomical Observatory, Mykolayiv National University, \\ Nikolska, 24, Mykolayiv, Ukraine, email: tajgeta@sp.mk.ua \\ ${ }^{4}$ Jan Kochanowski University, Institute of Physics, \\ ul. Swiętokrzyska, 15, 406 Kielce, Poland, e-mail: sfflin@cyf-kr.edu.pl,
} (Received January 12, 2012; received in final form August 27, 2012)

\begin{abstract}
The analysis of Tully's groups of galaxies belonging to the Local Supercluster (LSC) was performed. In the 1975 Hawley and Peebles [D. I. Hawley, P. J. E. Peebles, Astron. J. 80, 477 (1975)] presented the method for investigations of the galaxies orientation in the large structures. In our previous papers [W. Godłowski, P. Piwowarska, E. Panko, P. Flin, Astron. J. 723, 985 (2010); W. Godłowski, Astrophys. J. 747, 7 (2012)] the statistical test proposed by Hawley and Peebles for the investigation of this problem was analyzed in detail and some improvements were suggested. On this basis the new method of the analysis of galactic alignment in clusters was proposed. Using this method, Godłowski [W. Godłowski, Acta Phys. Polon. B 42, 2323 (2011)] analyzed the orientation of galaxies inside Tully's groups founding no significant deviations from isotropy both in orientation of position angles and $\delta_{D}$ and $\eta$ angles as well, giving the spatial orientation of galaxy planes. In the present paper we examined carefully and methodically the dependence of alignment in Tully's groups on the morphological type of galaxies. Moreover, we discussed the consequences of different approximation of "true shape" of the galaxies for different morphological types, a possible influence of this problem for the investigation of spatial orientation of galaxies. In addition, we discussed the implications of the obtained results for the theory of galaxy formation as well.
\end{abstract}

Key words: angular momenta, galaxies.

PACS number(s): 98.65.-r, 98.62.Ai

\section{INTRODUCTION}

The aspect of the structure formation in the Universe is one of the crucial problems of modern extragalactic astronomy and cosmology. Moreover, since different scenario of the structure formation predicts different orientations of galxies belonging to those structures [5-13], the investigation of the orientations of galaxies planes is regarded as a standard test of galaxies formation scenarios.

An interesting aspect of this problem consists in analysing the orientation of galaxies inside the galaxy structures. For the latest review of this problem see [14]. The very important question is whether there exists a dependence on the alignment to the mass of the analyzed structure or not. Godłowski et al. [15] suggested that the alignment of galaxies in a cluster should increase with the number of particular objects in the individual cluster. That hypothesis was confirmed qualitatively by Aryal et al. [16]. Godłowski et al. [2] verified this suggestion analysing sample of 247 rich Abell clusters using statistical tests to reveal the alignment increas with the richness of the clusters.
Another aspect of this problem concerns the orientation of galaxies in less massive, poor galaxy structures groups of galaxies. It should be noticed that for groups and clusters of galaxies there is no evidence of rotation. Moreover, Hwang and Lee [17] examined dispersions and velocity gradient of 899 Abell clusters and found a possible rotation in only six of them. Thus, any non-zero angular momentum of groups and clusters of galaxies would just come from a possible alignment of galaxy spins.

The orientation of galaxies in clusters has been investigated many times. Thompson [18] found alignment of galaxy orientations in the Virgo and A2197 clusters. Adams [19] discovered a bimodal distribution of galaxy orientations by examining the combined data for seven galaxy clusters (A76, A179, A194, A195, A999, A1016, A2197). The orientation of principal axes of the clusters corresponded with one of those maxima. Helou and Salpeter [20], studying 20 galaxies belonging to the Virgo cluster, found that their spins are not directed in random. However the nature of this nonrandom distribution was not too clear. MacGillivray and Dodd [21] investigated the distribution of the orientation of galaxies in

\footnotetext{
*Presented at The Sixth Scientific Conference "Selected Issues of Astronomy and Astrophysics" in honor of Bohdan Babiy, 4-6 October 2011, Lviv.
} 
the Virgo cluster and showed that the galaxy planes are perpendicular to "the direction towards the cluster's center", i.e. the galaxies' rotational axes are aligned towards that center.

On the other hand, Bukhari [22] as well as Bukhari and Cram [23] studying orientation of galaxies within clusters, did not recognize any alignment. Han et al [24] probed a region of the LSC with an enhanced density galaxies. They analyzed a sample of 60 galaxies with wellknown spins founding no alignment. Flin and Olowin [25] Trevese et al. [26] and Kim [27] investigating isolated Abell clusters, detected just rudimentary traces of alignment. Similar results were obtained by Torlina et al. [28] from the studies of the Coma cluster and its vicinity. Gonzalez and Teodoro [29] interpreted the alignment of just the brightest galaxies within a cluster as an effect of action of gravitational tidal forces.

Summing up the results obtained by various authors, it can be stated that we have no satisfactory evidence to support the galaxy axis alignment in the groups and poor clusters of galaxies, while there is ample evidence of this kind for the rich clusters of galaxies. Additionally, it is obvious that in the isolated Abell groups the brightest galaxies manifest a rudimentary alignment, [25-27] while in the most numerous clusters a non-random galaxy orientation alignment was found [16,30-34].

The alignment of galaxies in the Tully's groups of galaxies [35] was analyzed for the first time by Godłowski and Ostrowski [36]. For each cluster they studied the $\Delta_{11}$ parameter describing the galactic axes alignment with respect to a chosen cluster pole divided by its formal error $\sigma\left(\Delta_{11}\right)\left(s \equiv \Delta_{11} / \sigma\left(\Delta_{11}\right)\right)$. The cluster pole coordinates change along the entire celestial sphere. The resulting maps were analyzed for the correlations of their maxima with the important points on the maps. It was found that the maxima correlate well with the direction of the line of sight. Godłowski and Ostrowski [36] concluded that this strong and systematic effect was generated by the process of galactic axis de-projection from its optical image, being present in the catalogue data.

Tully's groups were investigated again by Godłowski et al. [15]. In that paper it was found that the groups do not exhibit a clear evidence for the existence of the alignment in the investigated structure. However, they concluded that the observational effect generated by the process of de-projection of galaxies [36] and later confirmed by $[30,31]$ mask any possible alignment with a high degree. For that reason more detailed studies of the orientation of a galaxy in Tully's groups of galaxies were required. In the paper by Godłowski [4] it was shown that using "a true shape" i. e. the true axis ratio of galaxies $q_{0}$ depending on the morphological type according to Heidmann et al. [37] (hereafter HHV) with the help of Fouque \& Paturel [38] (hereafter FP) corrections of $q$ to standard photometrical axial ratios allowed us to avoid this problem. This gives much more powerful investigations of the spatial orientation of galaxies.

Moreover, using a new method of the analysis of the galactic alignment in clusters proposed by [3] on the basis of the statistical test proposed by Hawley and Pee- bles [1], Godłowski [4] analyzed the orientation of galaxies inside Tully's groups founding no significant deviation from isotropy both in the orientation of the position angles and $\delta_{D}$ and $\eta$ angles giving the spatial orientation of galaxy planes. In the present paper we analyzed the dependence of the alignment in Tully's groups on the morphological type of galaxies.

\section{OBSERVATIONAL DATA}

We analyzed the alignment of galaxies in the galaxy groups belonging to the LSC. The groups were taken from Tully Nearby Galaxies (NBG) listed in the Catalogue [35]. This Catalogue contains 2367 galaxies with radial velocities less than $3000 \mathrm{~km} \mathrm{~s}^{-1}$ which give the posibility of remove the background objects. Tully's Catalogue provides a relatively uniform coverage of the entire unobscured sky [39]. The Catalogue does not contain the information about the position angles of galaxies. It is the reason the position angles were taken from [40-43] while some missing measurements were made on Palomar Sky Survey prints by Flin [44]. The NBG Catalogue gives the group affiliation for the galaxies belonging to the catalogue. In our opinion, the groups extracted from the NBG Catalogue are one of the best selections with the precise criterion of groups membership. The galaxy distances are based on velocities, assuming the flat cosmological model $\left(q_{0}=1 / 2\right)$ with $H_{0}=75 \mathrm{~km} \mathrm{~s}^{-1} \mathrm{Mpc}^{-1}$ and the model describing velocity perturbations in the vicinity of the Virgo Cluster [45] It means that the galaxy distances are very good and uniformly determined. As a result the lists of galaxies belonging to the particular groups are free from the foreground and background objects which is crucial in such a type of analysis. For our study we use only those groups from the NBC Catalogue which have at least 40 members.

\section{METHODS OF THE INVESTIGATION}

One should note that two main methods for the study of the galaxy orientation have been proposed uptill now. In the first one [1] the distribution of the position angle of the galactic image major axis was analyzed. The second approach is based on the de-projection of the galaxy images where the galaxy's inclination with respect to the observer's line of sight $i$ is considered. The latter method allowed us to use also the face-on galaxies in contrast to the investigations of the position angles where face-on and nearly face-on galaxies should be excluded from the consideration. This method was originally proposed by Öpik [46], applied by Jaaniste \& Sarr [47] and significantly modified by Flin \& Godłowski [44, 48-52] (see also [53]).

In the Tully's NBG Catalogue [35] the inclination angle was calculated according to the formula: $i=$ $\cos ^{-1}\left(q^{2}-q_{0}^{2}\right) /\left(1-q_{0}^{2}\right)^{-1 / 2}+3^{\circ}$, where $q=d / D$ is the ratio of the minor to the major axis diameters and $q_{0}$ is the "true" axial ratio. Tully used a standard value 
$q_{0}=0.2$. It is worth noting is that above formula is the modified Holmberg's [54] formula for oblate spheroids. For each galaxy, two angles are determined: $\delta_{D}$ is the angle between the normal to the galaxy plane and the main plane of the coordinate system, and $\eta$ is the angle between the projection of this normal onto the main plane and the direction towards the zero initial meridian. Using the Supergalactic coordinate system (Flin \& Godłowski [48] based on [55]) the following relations between the angles $(L, B, P)$ and $\left(\delta_{D}, \eta\right)$ are held:

$$
\begin{aligned}
& \sin \delta_{D}=-\cos i \sin B \pm \sin i \cos r \cos B, \\
\sin \eta & =\left(\cos \delta_{D}\right)^{-1}[-\cos i \cos B \sin L \\
& +\sin i(\mp \cos r \sin B \sin L \pm \sin r \cos L)], \\
\cos \eta & =\left(\cos \delta_{D}\right)^{-1}[-\cos i \cos B \cos L \\
& +\sin i(\mp \cos r \sin B \cos L \mp \sin r \sin L)],
\end{aligned}
$$

where $r=P-\pi / 2$.

In order to detect the non-random effects in the distribution of the investigated angles: $\delta_{D}, \eta$ and $P$ we divided the entire range of the analyzed angles into 18 bins and carried out three different statistical tests. These tests were: the $\chi^{2}$ test, the autocorrelation test and the Fourier test $[1-3,51,52]$.

Let $N$ denote the total number of galaxies in the considered cluster, and $N_{k}$ is the number of galaxies with the orientations within the $k$-th angular bin. Moreover $N_{0, k}$ denotes the expected number of galaxies in the $k$ th bin. In our case all $N_{0, k}$ equal $N_{0}$, which is also the mean number of galaxies per bin.

Our first test is the $\chi^{2}$ test:

$$
\chi^{2}=\sum_{k=1}^{n} \frac{\left(N_{k}-N p_{k}\right)^{2}}{N p_{k}}=\sum_{k=1}^{n} \frac{\left(N_{k}-N_{0, k}\right)^{2}}{N_{0, k}}
$$

where $p_{k}$ is the probability that the chosen galaxy falls into the $k$ th bin. We divided the entire range of a $\theta$ angle into $n$ bins, which gives $(n-1)$ degrees of freedom in the $\chi^{2}$ test. It means that the expected value $E\left(\chi^{2}\right)=n-1$ while the variance $\sigma^{2}\left(\chi^{2}\right)=2(n-1)$. For $n=18$ the $\chi^{2}$ test yields a critical value 27.59 (at the significance level $\alpha=0.05$ ).

The second auto-correlation test quantifies the correlations between the galaxy numbers in the neighboring angle bins. The measure of the correlation is defined as:

$$
C=\sum_{k=1}^{n} \frac{\left(N_{k}-N_{0, k}\right)\left(N_{k+1}-N_{0, k+1}\right)}{\left[N_{0, k} N_{0, k+1}\right]^{1 / 2}},
$$

where $N_{n+1}=N_{1}$. Hawley and Peebles [1] noted that in the case of an isotropic distribution we expect $C=0$ with the standard deviation $\sigma(C)=n^{1 / 2}$. Godłowski [3], analysing the case that all $N_{0, k}$ were equal, showed that in these case the expected value $E(C)=-1$, while the critical value for the autocorrelation test was $C_{c r} \approx 6.89$. The latter value was obtained from numerical simulations using the method described by Godłowski [3].
If the deviation from isotropy is a slowly varying function of the angle $\theta$ one can use the Fourier test $[1,51,52]$ :

$$
N_{k}=N_{0, k}\left(1+\Delta_{11} \cos 2 \theta_{k}+\Delta_{21} \sin 2 \theta_{k}\right),
$$

we obtain the following expressions for the $\Delta_{i 1}$ coefficients:

$$
\begin{aligned}
& \Delta_{11}=\frac{\sum_{k=1}^{n}\left(N_{k}-N_{0, k}\right) \cos 2 \theta_{k}}{\sum_{k=1}^{n} N_{0, k} \cos ^{2} 2 \theta_{k}}, \\
& \Delta_{21}=\frac{\sum_{k=1}^{n}\left(N_{k}-N_{0, k}\right) \sin 2 \theta_{k}}{\sum_{k=1}^{n} N_{0, k} \sin ^{2} 2 \theta_{k}} .
\end{aligned}
$$

The standard deviation of $\sigma\left(\Delta_{11}\right)$ and $\sigma\left(\Delta_{12}\right)$ is given by the expressions:

$$
\begin{gathered}
\sigma\left(\Delta_{11}\right)=\left(\sum_{k=1}^{n} N_{0, k} \cos ^{2} 2 \theta_{k}\right)^{-1 / 2} \approx\left(\frac{2}{n N_{0}}\right)^{1 / 2} \\
\sigma\left(\Delta_{21}\right)=\left(\sum_{k=1}^{n} N_{0, k} \sin ^{2} 2 \theta_{k}\right)^{-1 / 2} \approx\left(\frac{2}{n N_{0}}\right)^{1 / 2}
\end{gathered}
$$

The probability that the amplitude

$$
\Delta_{1}=\left(\Delta_{11}^{2}+\Delta_{21}^{2}\right)^{1 / 2}
$$

is greater than a certain chosen value is given by the formula:

$$
P\left(>\Delta_{1}\right)=\exp \left(-\frac{n}{4} N_{0} \Delta_{1}^{2}\right)
$$

This test was substantially improved by Godłowski for the case when a higher Fourier mode is taken into account:

$$
\begin{aligned}
N_{k} & =N_{0, k}\left(1+\Delta_{11} \cos 2 \theta_{k}+\Delta_{21} \sin 2 \theta_{k}\right. \\
& \left.+\Delta_{12} \cos 4 \theta_{k}+\Delta_{22} \sin 4 \theta_{k}+\ldots\right) .
\end{aligned}
$$

In this case the amplitude $\Delta$ instead $\Delta_{1}$ is considered. When we investigate a simple case of position angles distribution, $\Delta^{2}$ is given by simple formula: $\Delta^{2}=$ $\Delta_{11}^{2}+\Delta_{21}^{2}+\Delta_{12}^{2}+\Delta_{22}^{2}$ (see $[3,52]$ for details).

The isotropy of the resultant distributions of the investigated angles was also analyzed by the KolmogorovSmirnov test (K-S test). We assumed that the theoretical, random distribution contains the same number of objects as the observed one. In order to reject the $H_{0}$ hypothesis that the distribution is the random one the value of observed statistics $\lambda$ should be greater than $\lambda_{\text {cr }}=1.358$ (for $\alpha=0.05$ ). However, one should note, that especially in the case of position angles the number of analyzed galaxies is sometimes small and does not satisfy theoretical tests conditions. That is the reason why we repeated our analysis with different numbers of bins, and revealed insignificant differences in these cases. 


\section{THE RESULTS}

The results were presented in the Tables 1-20. At first, we analyzed the orientation of galaxies in Tully's groups using, for obtaining $\delta_{D}$ and $\eta$ angles, inclinations angles taken directly from NBG Catalogue [35] (sample A). These results were shown in Tables 1-9.

For the sample of All galaxies the analysis of the supergalactic position angles has shown that only one group (61) exhibits the alignment of galaxies. The analysis of the distribution of the angles giving spatial orientation of galaxies $\left(\delta_{D}\right.$ and $\left.\eta\right)$ seems to show a weak alignment. For the $\delta_{D}$ angle the tests showed that the distributions can be non random in the case of the clusters 11, 31, 51 41 and 52. For $\eta$ angle we found a possible alignment in the case of clusters $11,12,41,52,64,31$ and 51 . However, in the paper by Godłowski [4] it was shown that this alignment is disappeared when we avoid the assumption that the "true" axial ratio is $q_{0}=0.2$, which is a rather poor approximation, especially for the non-spiral galaxies. Since of the NBG Catalogue contains morphological types of galaxies it allowed us to use different values of $q_{0}$ depending on the morphological type [37]. With the help of Fouque \& Paturel [38] formulae, which convert $q$ to the standard photometrical axial ratios, the new inclination angle $i$ for all galaxies in the NGB catalogue was computed. The results of our investigations for that "new" sample of galaxies (sample B) are presented in Tables 10-18. Please, note that the above procedure does not change the position angles of galaxies, instead of the case of position angle $P$, sample B is related to only those galaxies were the surely measured angles were taking into account.

\begin{tabular}{|c|c|c|c|c|c|c|c|}
\hline angle & group & $\chi^{2}$ & $C$ & $P\left(\Delta_{1}\right)$ & $P(\Delta)$ & $\lambda$ & $\Delta_{11} / \sigma\left(\Delta_{11}\right)$ \\
\hline \multirow{6}{*}{} & 11 & 62.8 & 9.50 & 0.000 & 0.000 & 1.20 & -4.09 \\
& 12 & 25.7 & -11.48 & 0.299 & 0.634 & 0.55 & -1.56 \\
& 13 & 29.7 & -6.94 & 0.915 & 0.944 & 0.62 & 0.02 \\
& 14 & 24.0 & 3.52 & 0.170 & 0.254 & 0.78 & -1.69 \\
& 15 & 13.1 & -1.88 & 0.791 & 0.729 & 0.59 & -0.03 \\
& 17 & 13.8 & -5.50 & 0.621 & 0.743 & 0.82 & -0.61 \\
& 21 & 14.2 & 0.24 & 0.120 & 0.299 & 1.14 & -0.38 \\
& 22 & 7.0 & 0.68 & 0.546 & 0.857 & 0.62 & 0.75 \\
& 23 & 17.0 & -1.82 & 0.613 & 0.701 & 0.47 & 0.96 \\
& 31 & 33.7 & 15.98 & 0.000 & 0.002 & 1.79 & 1.36 \\
& 41 & 22.8 & 6.54 & 0.049 & 0.012 & 1.37 & -0.04 \\
& 42 & 24.7 & -3.78 & 0.401 & 0.444 & 0.75 & 0.58 \\
& 44 & 26.7 & 7.95 & 0.047 & 0.050 & 1.34 & -1.22 \\
& 51 & 29.6 & -0.41 & 0.025 & 0.018 & 1.44 & 0.96 \\
& 52 & 21.6 & 3.04 & 0.011 & 0.040 & 1.42 & -1.81 \\
& 53 & 13.3 & -3.29 & 0.556 & 0.821 & 0.62 & -0.60 \\
& 61 & 19.9 & -3.13 & 0.834 & 0.175 & 0.62 & -0.54 \\
& 64 & 28.7 & -7.54 & 0.180 & 0.488 & 0.84 & 0.55 \\
\hline
\end{tabular}

Table 1. Test for isotropy of the orientations of the galaxy plane. The distribution of the angle $\delta$ of galaxies, inclination was taken directly from the NGC Catalogue.

\begin{tabular}{|c|c|c|c|c|c|c|c|}
\hline angle & group & $\chi^{2}$ & $C$ & $P\left(\Delta_{1}\right)$ & $P(\Delta)$ & $\lambda$ & $\Delta_{11} / \sigma\left(\Delta_{11}\right)$ \\
\hline & 11 & 27.6 & -1.85 & 0.278 & 0.517 & 0.68 & -1.59 \\
& 12 & 21.3 & -9.50 & 0.582 & 0.844 & 0.41 & -1.01 \\
& 13 & 30.4 & -9.00 & 0.314 & 0.281 & 0.69 & 1.34 \\
& 14 & 15.4 & -1.25 & 0.907 & 0.635 & 0.43 & 0.37 \\
& 15 & 12.9 & -1.51 & 0.595 & 0.729 & 0.72 & 0.79 \\
& 17 & 13.6 & -8.66 & 0.947 & 0.975 & 0.46 & -0.13 \\
& 21 & 12.3 & -0.52 & 0.636 & 0.403 & 0.64 & 0.17 \\
& 22 & 17.7 & -0.69 & 0.063 & 0.197 & 1.12 & 1.63 \\
& 23 & 15.7 & -1.34 & 0.377 & 0.393 & 0.77 & 1.18 \\
& 31 & 22.9 & 4.52 & 0.024 & 0.105 & 1.27 & 1.07 \\
& 41 & 22.9 & 4.91 & 0.487 & 0.033 & 0.80 & 0.18 \\
& 42 & 20.2 & -4.17 & 0.807 & 0.303 & 0.60 & 0.58 \\
& 44 & 12.9 & 0.83 & 0.371 & 0.453 & 0.63 & -1.04 \\
& 51 & 16.6 & -4.99 & 0.729 & 0.582 & 0.55 & 0.53 \\
& 52 & 19.0 & -1.47 & 0.057 & 0.213 & 1.07 & -1.59 \\
& 53 & 19.7 & -1.92 & 0.120 & 0.196 & 1.05 & -1.20 \\
& 61 & 19.0 & -5.70 & 0.565 & 0.392 & 0.65 & 0.37 \\
& 64 & 20.7 & -2.31 & 0.789 & 0.668 & 0.37 & 0.29 \\
\hline \multirow{6}{*}{$\delta$}
\end{tabular}

Table 2. Test for isotropy of the orientations of the galaxy plane. The distribution of the angle $\delta$ of galaxies, SP galaxies, inclination was taken directly from the NGC Catalogue. 
SOME ASPECTS OF THE ORIENTATION OF GALAXIES IN CLUSTERS

\begin{tabular}{|c|c|c|c|c|c|c|c|}
\hline angle & group & $\chi^{2}$ & $C$ & $P\left(\Delta_{1}\right)$ & $P(\Delta)$ & $\lambda$ & $\Delta_{11} / \sigma\left(\Delta_{11}\right)$ \\
\hline \multirow{18}{*}{$\delta$} & 11 & 93.3 & 4.00 & 0.000 & 0.000 & 1.80 & -5.10 \\
\hline & 12 & 26.6 & -5.46 & 0.362 & 0.481 & 0.75 & -1.35 \\
\hline & 13 & 34.6 & -1.84 & 0.274 & 0.125 & 0.69 & -1.60 \\
\hline & 14 & 26.3 & 8.14 & 0.011 & 0.689 & 1.07 & -2.67 \\
\hline & 15 & 21.5 & 4.03 & 0.027 & 0.060 & 1.48 & -1.34 \\
\hline & 17 & 11.9 & 0.45 & 0.526 & 0.688 & 0.72 & -0.79 \\
\hline & 21 & 32.9 & -3.95 & 0.038 & 0.077 & 1.58 & -1.01 \\
\hline & 22 & 15.3 & -1.46 & 0.440 & 0.396 & 0.96 & -0.91 \\
\hline & 23 & 13.3 & -1.20 & 0.735 & 0.724 & 0.73 & -0.10 \\
\hline & 31 & 27.0 & 5.30 & 0.007 & 0.468 & 1.45 & 0.87 \\
\hline & 41 & 18.1 & 1.02 & 0.038 & 0.491 & 1.39 & -0.31 \\
\hline & 42 & 21.8 & 2.01 & 0.195 & 0.472 & 1.07 & 0.17 \\
\hline & 44 & 22.5 & 7.63 & 0.052 & 0.126 & 1.40 & -0.64 \\
\hline & 51 & 33.3 & 7.58 & 0.001 & 0.033 & 2.05 & 0.94 \\
\hline & 52 & 22.9 & 2.63 & 0.160 & 0.058 & 1.23 & -0.90 \\
\hline & 53 & 32.1 & 14.22 & 0.000 & 0.136 & 2.01 & 0.73 \\
\hline & 61 & 23.6 & 0.99 & 0.094 & 0.035 & 1.03 & -1.77 \\
\hline & 64 & 23.2 & -0.18 & 0.090 & 0.453 & 1.17 & 0.53 \\
\hline
\end{tabular}

Table 3. Test for isotropy of the orientations of the galaxy plane. The distribution of the angle $\delta$ of galaxies, the NSP galaxies, inclination was taken directly from the NGC Catalogue.

\begin{tabular}{|c|c|c|c|c|c|c|c|}
\hline angle & group & $\chi^{2}$ & $C$ & $P\left(\Delta_{1}\right)$ & $P(\Delta)$ & $\lambda$ & $\Delta_{11} / \sigma\left(\Delta_{11}\right)$ \\
\hline \multirow{6}{*}{} & 11 & 60.0 & 5.96 & 0.000 & 0.000 & 2.00 & -4.09 \\
& 12 & 28.5 & 7.56 & 0.001 & 0.010 & 1.70 & -1.56 \\
& 13 & 25.6 & 2.78 & 0.079 & 0.105 & 0.77 & 0.02 \\
& 14 & 27.4 & 6.63 & 0.090 & 0.148 & 1.00 & -1.69 \\
& 15 & 22.9 & 2.51 & 0.764 & 0.209 & 0.91 & -0.03 \\
& 17 & 13.1 & -5.97 & 0.470 & 0.820 & 0.46 & -0.61 \\
& 21 & 26.9 & -3.55 & 0.054 & 0.202 & 1.23 & -0.38 \\
& 22 & 11.7 & 5.57 & 0.177 & 0.224 & 0.98 & 0.75 \\
& 23 & 20.2 & -0.10 & 0.081 & 0.232 & 1.09 & 0.96 \\
& 31 & 24.0 & 0.43 & 0.046 & 0.036 & 1.56 & 1.36 \\
& 41 & 27.2 & 10.22 & 0.001 & 0.002 & 1.95 & -0.04 \\
& 42 & 15.9 & 3.30 & 0.033 & 0.069 & 1.24 & 0.58 \\
& 44 & 20.4 & -3.05 & 0.226 & 0.138 & 0.78 & -1.22 \\
& 51 & 30.6 & -5.37 & 0.042 & 0.125 & 1.15 & 0.96 \\
& 52 & 38.1 & 12.29 & 0.001 & 0.001 & 1.92 & -1.81 \\
& 53 & 12.2 & -8.28 & 0.816 & 0.949 & 0.34 & -0.60 \\
& 61 & 23.7 & -12.56 & 0.549 & 0.511 & 0.64 & -0.54 \\
& 64 & 50.1 & -3.53 & 0.002 & 0.000 & 1.88 & 0.55 \\
\hline
\end{tabular}

Table 4. Test for isotropy of the orientations of the galaxy plane. The distribution of the angle $\eta$ of galaxies, inclination was taken directly from the NGC Catalogue. 
P. PAJOWSKA, W. GODŁOWSKI, E. PANKO, P. FLIN

\begin{tabular}{|c|c|c|c|c|c|c|c|}
\hline angle & group & $\chi^{2}$ & $C$ & $P\left(\Delta_{1}\right)$ & $P(\Delta)$ & $\lambda$ & $\Delta_{11} / \sigma\left(\Delta_{11}\right)$ \\
\hline \multirow{6}{7}{} & 11 & 32.1 & -3.44 & 0.070 & 0.043 & 1.17 & 2.30 \\
& 12 & 18.7 & 2.93 & 0.099 & 0.133 & 1.17 & -0.17 \\
& 13 & 25.8 & 1.92 & 0.519 & 0.115 & 1.16 & 1.04 \\
& 14 & 12.9 & 0.37 & 0.372 & 0.356 & 0.71 & -1.38 \\
& 15 & 25.5 & 2.89 & 0.537 & 0.168 & 0.97 & 0.63 \\
& 17 & 8.0 & -2.57 & 0.707 & 0.948 & 0.67 & 0.48 \\
& 21 & 14.6 & 1.00 & 0.216 & 0.424 & 0.89 & 1.12 \\
& 22 & 16.3 & 3.92 & 0.481 & 0.142 & 0.87 & 1.10 \\
& 23 & 14.5 & -2.73 & 0.777 & 0.884 & 0.44 & -0.34 \\
& 31 & 22.7 & 1.27 & 0.181 & 0.079 & 1.38 & 1.19 \\
& 41 & 16.3 & 6.14 & 0.023 & 0.069 & 1.34 & 2.48 \\
& 42 & 13.4 & -6.50 & 0.712 & 0.947 & 0.48 & -0.09 \\
& 44 & 16.5 & -5.62 & 0.308 & 0.427 & 0.59 & 1.17 \\
& 51 & 34.8 & -6.10 & 0.421 & 0.603 & 0.98 & 0.69 \\
& 52 & 25.8 & 4.05 & 0.043 & 0.092 & 1.19 & 1.06 \\
& 53 & 16.6 & -8.13 & 0.423 & 0.623 & 0.53 & 0.30 \\
& 61 & 24.5 & -7.82 & 0.343 & 0.159 & 1.14 & 0.83 \\
& 64 & 20.2 & -5.73 & 0.339 & 0.281 & 0.86 & 1.21 \\
\hline
\end{tabular}

Table 5. Test for isotropy of the orientations of the galaxy plane. The distribution of the angle $\eta$ of galaxies, SP galaxies, inclination was taken directly from the NGC Catalogue.

\begin{tabular}{|c|c|c|c|c|c|c|c|}
\hline angle & group & $\chi^{2}$ & $C$ & $P\left(\Delta_{1}\right)$ & $P(\Delta)$ & $\lambda$ & $\Delta_{11} / \sigma\left(\Delta_{11}\right)$ \\
\hline \multirow{6}{7}{} & 11 & 67.2 & 32.17 & 0.000 & 0.000 & 1.92 & 6.53 \\
& 12 & 26.6 & 12.58 & 0.002 & 0.003 & 1.40 & -1.45 \\
& 13 & 22.1 & -1.12 & 0.097 & 0.164 & 1.19 & 1.78 \\
& 14 & 52.4 & 16.75 & 0.001 & 0.001 & 1.53 & 2.45 \\
& 15 & 13.0 & 3.00 & 0.879 & 0.264 & 0.50 & -0.46 \\
& 17 & 18.9 & -0.12 & 0.019 & 0.091 & 1.24 & -1.14 \\
& 21 & 32.6 & -10.03 & 0.066 & 0.195 & 0.89 & -0.58 \\
& 22 & 6.4 & 1.35 & 0.309 & 0.523 & 0.56 & 1.09 \\
& 23 & 22.5 & 3.08 & 0.006 & 0.036 & 1.39 & -1.71 \\
& 31 & 13.8 & 0.27 & 0.139 & 0.407 & 0.91 & 1.91 \\
& 41 & 26.7 & 2.18 & 0.019 & 0.047 & 1.48 & 1.59 \\
& 42 & 30.5 & 13.91 & 0.001 & 0.000 & 1.89 & 0.87 \\
& 44 & 23.4 & -3.57 & 0.551 & 0.390 & 0.94 & -0.01 \\
& 51 & 25.2 & 6.91 & 0.006 & 0.013 & 0.96 & 3.21 \\
& 52 & 27.2 & 14.91 & 0.009 & 0.001 & 1.78 & 2.08 \\
& 53 & 8.3 & -1.85 & 0.695 & 0.899 & 0.38 & -0.31 \\
& 61 & 22.8 & 0.00 & 0.012 & 0.048 & 1.38 & 0.63 \\
& 64 & 47.0 & 5.50 & 0.001 & 0.000 & 2.00 & 3.19 \\
\hline
\end{tabular}

Table 6. Test for isotropy of the orientations of the galaxy plane. The distribution of the angle $\eta$ of galaxies, NSP galaxies, inclination was taken directly from NGC Catalogue. 
SOME ASPECTS OF THE ORIENTATION OF GALAXIES IN CLUSTERS

\begin{tabular}{|c|c|c|c|c|c|c|c|}
\hline angle & group & $\chi^{2}$ & $C$ & $P\left(\Delta_{1}\right)$ & $P(\Delta)$ & $\lambda$ & $\Delta_{11} / \sigma\left(\Delta_{11}\right)$ \\
\hline \multirow{6}{*}{} & 11 & 22.7 & -11.42 & 0.728 & 0.756 & 0.53 & 0.78 \\
& 12 & 17.6 & -1.57 & 0.198 & 0.302 & 0.88 & -0.61 \\
& 13 & 13.4 & -2.48 & 0.714 & 0.621 & 0.41 & -0.28 \\
& 14 & 14.9 & -1.05 & 0.990 & 0.204 & 0.49 & -0.09 \\
& 15 & 11.3 & -0.75 & 0.185 & 0.382 & 1.06 & -0.03 \\
& 17 & 10.7 & -5.64 & 0.727 & 0.734 & 0.62 & -0.50 \\
& 21 & 13.5 & -2.84 & 0.878 & 0.936 & 0.67 & -0.38 \\
& 22 & 16.0 & -1.98 & 0.910 & 0.895 & 0.63 & -0.41 \\
& 23 & 12.3 & 0.27 & 0.230 & 0.453 & 0.81 & -1.37 \\
& 31 & 20.1 & 1.00 & 0.729 & 0.204 & 0.82 & 0.46 \\
& 41 & 20.0 & 10.67 & 0.595 & 0.005 & 1.09 & -0.58 \\
& 42 & 19.0 & 1.51 & 0.124 & 0.222 & 0.91 & -1.51 \\
& 44 & 18.9 & 1.64 & 0.367 & 0.726 & 0.98 & 0.57 \\
& 51 & 23.1 & 3.00 & 0.576 & 0.045 & 0.88 & -1.04 \\
& 52 & 14.8 & -0.32 & 0.631 & 0.798 & 0.77 & 0.77 \\
& 53 & 17.5 & 2.82 & 0.080 & 0.192 & 1.36 & 1.61 \\
& 61 & 27.9 & 6.48 & 0.007 & 0.002 & 1.68 & -0.76 \\
& 64 & 18.4 & 2.10 & 0.295 & 0.419 & 0.91 & -1.56 \\
\hline
\end{tabular}

Table 7. Test for isotropy of the orientations of the galaxy plane. The distribution of the angle $P$ of galaxies.

\begin{tabular}{|c|c|c|c|c|c|c|c|}
\hline angle & group & $\chi^{2}$ & $C$ & $P\left(\Delta_{1}\right)$ & $P(\Delta)$ & $\lambda$ & $\Delta_{11} / \sigma\left(\Delta_{11}\right)$ \\
\hline \multirow{18}{*}{$P$} & 11 & 21.8 & -9.88 & 0.821 & 0.853 & 0.50 & -0.18 \\
\hline & 12 & 14.1 & 0.55 & 0.173 & 0.339 & 0.86 & -0.54 \\
\hline & 13 & 15.6 & 4.80 & 0.430 & 0.073 & 0.79 & -1.21 \\
\hline & 14 & 16.3 & 4.30 & 0.326 & 0.167 & 0.74 & -0.65 \\
\hline & 15 & 12.2 & -2.00 & 0.294 & 0.566 & 0.96 & -0.38 \\
\hline & 17 & 11.7 & -5.00 & 0.702 & 0.733 & 0.62 & 0.00 \\
\hline & 21 & 22.2 & -8.00 & 0.577 & 0.636 & 0.93 & -1.03 \\
\hline & 22 & 16.3 & -1.67 & 0.416 & 0.717 & 0.77 & -1.28 \\
\hline & 23 & 12.8 & 1.69 & 0.272 & 0.270 & 0.78 & -0.74 \\
\hline & 31 & 14.1 & -2.12 & 0.532 & 0.416 & 0.57 & -0.26 \\
\hline & 41 & 21.7 & 10.32 & 0.972 & 0.003 & 0.78 & -0.07 \\
\hline & 42 & 14.7 & 1.86 & 0.146 & 0.194 & 0.80 & -1.02 \\
\hline & 44 & 16.0 & -3.00 & 0.371 & 0.700 & 0.71 & 0.46 \\
\hline & 51 & 23.9 & -0.67 & 0.686 & 0.041 & 0.84 & -0.84 \\
\hline & 52 & 12.2 & -2.95 & 0.533 & 0.851 & 0.56 & 0.99 \\
\hline & 53 & 16.4 & -3.55 & 0.508 & 0.613 & 0.78 & 0.66 \\
\hline & 61 & 21.0 & 1.51 & 0.060 & 0.036 & 1.25 & -0.43 \\
\hline & 64 & 16.0 & 0.70 & 0.683 & 0.344 & 1.07 & -0.66 \\
\hline
\end{tabular}

Table 8. Test for isotropy of the orientations of the galaxy plane. The distribution of the angle $P$ of galaxies, SP galaxies. 
P. PAJOWSKA, W. GODŁOWSKI, E. PANKO, P. FLIN

\begin{tabular}{|c|c|c|c|c|c|c|c|}
\hline angle & group & $\chi^{2}$ & $C$ & $P\left(\Delta_{1}\right)$ & $P(\Delta)$ & $\lambda$ & $\Delta_{11} / \sigma\left(\Delta_{11}\right)$ \\
\hline \multirow{6}{*}{} & 11 & 22.7 & 4.66 & 0.044 & 0.031 & 0.81 & 1.99 \\
& 12 & 18.3 & -1.08 & 0.926 & 0.931 & 0.41 & -0.27 \\
& 13 & 14.2 & -2.90 & 0.475 & 0.432 & 0.57 & 1.04 \\
& 14 & 19.3 & -4.94 & 0.399 & 0.270 & 0.57 & 0.54 \\
& 15 & 18.8 & -2.80 & 0.451 & 0.326 & 1.02 & 0.68 \\
& 17 & 14.5 & -3.50 & 0.703 & 0.769 & 0.63 & -0.83 \\
& 21 & 16.9 & -7.35 & 0.604 & 0.846 & 0.36 & 0.96 \\
& 22 & 20.0 & -1.38 & 0.600 & 0.798 & 0.61 & 0.99 \\
& 23 & 26.4 & -7.00 & 0.269 & 0.379 & 0.65 & -1.54 \\
& 31 & 27.2 & 3.62 & 0.250 & 0.148 & 1.34 & 1.51 \\
& 41 & 11.0 & -0.25 & 0.312 & 0.526 & 0.86 & -0.96 \\
& 42 & 19.8 & -1.80 & 0.396 & 0.743 & 0.65 & -1.34 \\
& 44 & 16.1 & 0.71 & 0.898 & 0.844 & 0.84 & 0.34 \\
& 51 & 14.3 & 1.43 & 0.585 & 0.847 & 0.62 & -0.63 \\
& 52 & 30.0 & 6.00 & 0.104 & 0.045 & 1.73 & -0.19 \\
& 53 & 17.3 & 4.18 & 0.039 & 0.164 & 1.37 & 2.08 \\
& 61 & 16.9 & 5.29 & 0.051 & 0.067 & 1.34 & -0.90 \\
& 64 & 20.1 & 0.45 & 0.168 & 0.321 & 0.80 & -1.74 \\
\hline
\end{tabular}

Table 9. Test for isotropy of the orientations of the galaxy plane. The distribution of the angle $P$ of galaxies, NSP galaxies.

\begin{tabular}{|c|c|c|c|c|c|c|c|}
\hline angle & group & $\chi^{2}$ & $C$ & $P\left(\Delta_{1}\right)$ & $P(\Delta)$ & $\lambda$ & $\Delta_{11} / \sigma\left(\Delta_{11}\right)$ \\
\hline \multirow{6}{*}{} & 11 & 14.3 & -2.46 & 0.504 & 0.848 & 0.39 & -1.17 \\
& 12 & 12.4 & 2.49 & 0.749 & 0.680 & 0.37 & 0.74 \\
& 13 & 8.7 & 0.86 & 0.403 & 0.694 & 0.54 & 1.25 \\
& 14 & 22.7 & 1.50 & 0.658 & 0.466 & 0.52 & -0.89 \\
& 15 & 26.2 & 4.40 & 0.038 & 0.034 & 1.25 & 1.90 \\
& 17 & 7.0 & -1.57 & 0.959 & 0.917 & 0.48 & -0.11 \\
& 21 & 19.7 & 6.05 & 0.615 & 0.049 & 0.85 & 0.72 \\
& 22 & 17.9 & 1.77 & 0.062 & 0.128 & 1.30 & 1.44 \\
& 23 & 22.1 & -3.00 & 0.155 & 0.266 & 0.71 & 1.88 \\
& 31 & 19.1 & 3.90 & 0.095 & 0.245 & 0.74 & 0.50 \\
& 41 & 20.9 & -4.77 & 0.374 & 0.476 & 0.69 & 1.26 \\
& 42 & 18.3 & -4.08 & 0.462 & 0.293 & 0.86 & -0.95 \\
& 44 & 23.9 & 0.74 & 0.581 & 0.115 & 0.93 & -0.63 \\
& 51 & 18.3 & 3.40 & 0.826 & 0.851 & 0.61 & 0.32 \\
& 52 & 20.7 & 4.97 & 0.013 & 0.043 & 1.53 & -1.51 \\
& 53 & 13.2 & -1.46 & 0.696 & 0.720 & 0.62 & -0.67 \\
& 61 & 25.3 & -1.26 & 0.452 & 0.376 & 1.03 & -0.22 \\
& 64 & 25.9 & -1.99 & 0.227 & 0.354 & 0.78 & 0.06 \\
\hline
\end{tabular}

Table 10. Test for isotropy of the orientations of the galaxy plane. The distribution of the angle $\delta$ of galaxies, inclination was obtained according to HHD and PP corrections. 
SOME ASPECTS OF THE ORIENTATION OF GALAXIES IN CLUSTERS

\begin{tabular}{|c|c|c|c|c|c|c|c|}
\hline angle & group & $\chi^{2}$ & $C$ & $P\left(\Delta_{1}\right)$ & $P(\Delta)$ & $\lambda$ & $\Delta_{11} / \sigma\left(\Delta_{11}\right)$ \\
\hline \multirow{6}{*}{} & 11 & 19.7 & -4.98 & 0.894 & 0.402 & 0.44 & 0.36 \\
& 12 & 19.0 & -5.69 & 0.979 & 0.716 & 0.51 & 0.20 \\
& 13 & 29.4 & 1.55 & 0.085 & 0.066 & 0.85 & 2.01 \\
& 14 & 17.8 & 1.49 & 0.796 & 0.139 & 0.60 & 0.65 \\
& 15 & 18.6 & -4.82 & 0.330 & 0.624 & 0.93 & 0.96 \\
& 17 & 10.0 & -3.30 & 0.910 & 0.947 & 0.52 & 0.20 \\
& 21 & 19.6 & -3.88 & 0.794 & 0.176 & 0.89 & 0.41 \\
& 22 & 14.7 & 3.11 & 0.340 & 0.345 & 0.89 & 1.07 \\
& 23 & 16.0 & -3.46 & 0.258 & 0.359 & 0.77 & 1.36 \\
& 31 & 25.1 & -0.24 & 0.170 & 0.284 & 0.88 & 1.30 \\
& 41 & 16.7 & -2.21 & 0.616 & 0.229 & 0.66 & 0.44 \\
& 42 & 18.5 & 1.64 & 0.729 & 0.069 & 0.76 & 0.80 \\
& 44 & 7.9 & -1.11 & 0.583 & 0.869 & 0.46 & -0.94 \\
& 51 & 17.8 & -5.34 & 0.976 & 0.854 & 0.29 & 0.19 \\
& 52 & 17.6 & 5.95 & 0.010 & 0.054 & 1.23 & -1.88 \\
& 53 & 19.5 & 3.85 & 0.014 & 0.036 & 1.42 & -1.28 \\
& 61 & 22.8 & -2.37 & 0.128 & 0.223 & 1.06 & 1.40 \\
& 64 & 17.7 & 3.38 & 0.930 & 0.442 & 0.28 & 0.38 \\
& & & & & & & \\
& & & & & \\
& 54 & & &
\end{tabular}

Table 11. Test for isotropy of the orientations of the galaxy plane. The distribution of the angle $\delta$ of galaxies, SP galaxies, inclination was obtained according to HHD and PP corrections.

\begin{tabular}{|c|c|c|c|c|c|c|c|}
\hline angle & group & $\chi^{2}$ & $C$ & $P\left(\Delta_{1}\right)$ & $P(\Delta)$ & $\lambda$ & $\Delta_{11} / \sigma\left(\Delta_{11}\right)$ \\
\hline \multirow{6}{*}{} & 11 & 27.2 & 8.78 & 0.006 & 0.025 & 1.04 & -3.07 \\
& 12 & 21.0 & 6.47 & 0.091 & 0.035 & 0.92 & -2.18 \\
& 13 & 11.2 & 0.03 & 0.947 & 0.420 & 0.51 & 0.32 \\
& 14 & 14.4 & 7.68 & 0.613 & 0.115 & 0.55 & -0.61 \\
& 15 & 11.9 & 0.74 & 0.808 & 0.777 & 0.48 & -0.03 \\
& 17 & 6.7 & 1.16 & 0.900 & 0.815 & 0.39 & -0.01 \\
& 21 & 12.3 & -0.57 & 0.802 & 0.947 & 0.50 & -0.13 \\
& 22 & 21.0 & -1.43 & 0.900 & 0.965 & 0.52 & -0.30 \\
& 23 & 15.7 & 3.03 & 0.698 & 0.662 & 0.44 & 0.85 \\
& 31 & 16.4 & -3.81 & 0.428 & 0.522 & 0.71 & 0.23 \\
& 41 & 17.7 & -0.62 & 0.327 & 0.653 & 0.90 & 1.18 \\
& 42 & 10.2 & 2.47 & 0.384 & 0.745 & 0.58 & 1.07 \\
& 44 & 10.2 & 1.38 & 0.098 & 0.319 & 1.05 & -0.49 \\
& 51 & 11.0 & 3.12 & 0.271 & 0.511 & 0.84 & 0.96 \\
& 52 & 9.9 & 2.15 & 0.435 & 0.727 & 0.78 & 0.23 \\
& 53 & 26.5 & 9.98 & 0.005 & 0.008 & 1.56 & 0.67 \\
& 61 & 17.4 & 1.63 & 0.647 & 0.313 & 0.62 & -0.93 \\
& 64 & 19.7 & -1.93 & 0.226 & 0.443 & 0.76 & 0.29 \\
& & & & & & &
\end{tabular}

Table 12. Test for isotropy of the orientations of the galaxy plane. The distribution of the angle $\delta$ of galaxies, NSP galaxies, inclination was obtained according to HHD and PP corrections. 
P. PAJOWSKA, W. GODŁOWSKI, E. PANKO, P. FLIN

\begin{tabular}{|c|c|c|c|c|c|c|c|}
\hline angle & group & $\chi^{2}$ & $C$ & $P\left(\Delta_{1}\right)$ & $P(\Delta)$ & $\lambda$ & $\Delta_{11} / \sigma\left(\Delta_{11}\right)$ \\
\hline \multirow{7}{7}{} & 11 & 44.1 & 13.00 & 0.000 & 0.000 & 1.37 & 3.77 \\
& 12 & 21.3 & 3.87 & 0.075 & 0.126 & 1.65 & -0.90 \\
& 13 & 18.3 & 5.17 & 0.272 & 0.090 & 0.67 & 1.53 \\
& 14 & 8.5 & 0.34 & 0.418 & 0.638 & 0.45 & 0.55 \\
& 15 & 22.0 & -11.48 & 0.651 & 0.777 & 0.57 & 0.72 \\
& 17 & 8.2 & -3.05 & 0.603 & 0.852 & 0.40 & -0.65 \\
& 21 & 15.8 & -6.45 & 0.718 & 0.912 & 0.75 & 0.17 \\
& 22 & 14.6 & 1.00 & 0.767 & 0.964 & 0.53 & 0.73 \\
& 23 & 7.3 & -1.18 & 0.809 & 0.956 & 0.40 & 0.06 \\
& 31 & 20.2 & 0.17 & 0.047 & 0.103 & 0.81 & 2.31 \\
& 41 & 38.3 & 20.16 & 0.007 & 0.000 & 1.61 & 0.97 \\
& 42 & 20.6 & 4.94 & 0.729 & 0.023 & 0.59 & 0.80 \\
& 44 & 19.5 & -3.95 & 0.763 & 0.441 & 0.55 & -0.08 \\
& 51 & 20.8 & 2.61 & 0.736 & 0.137 & 0.66 & 0.71 \\
& 52 & 17.6 & -0.37 & 0.085 & 0.276 & 0.99 & 0.93 \\
& 53 & 19.3 & -3.50 & 0.888 & 0.361 & 0.51 & -0.06 \\
& 61 & 23.7 & 2.09 & 0.045 & 0.043 & 1.22 & 1.39 \\
& 64 & 23.3 & -5.65 & 0.289 & 0.291 & 0.76 & 1.46 \\
\hline
\end{tabular}

Table 13. Test for isotropy of the orientations of the galaxy plane. The distribution of the angle $\eta$ of galaxies, inclination was obtained according to HHD and PP corrections.

\begin{tabular}{|c|c|c|c|c|c|c|c|}
\hline angle & group & $\chi^{2}$ & $C$ & $P\left(\Delta_{1}\right)$ & $P(\Delta)$ & $\lambda$ & $\Delta_{11} / \sigma\left(\Delta_{11}\right)$ \\
\hline \multirow{6}{*}{} & 11 & 25.3 & 6.11 & 0.222 & 0.010 & 0.77 & 1.68 \\
& 12 & 19.6 & 3.51 & 0.673 & 0.264 & 0.77 & -0.12 \\
& 13 & 23.5 & 0.03 & 0.647 & 0.069 & 1.05 & 0.91 \\
& 14 & 16.9 & 0.28 & 0.289 & 0.348 & 0.78 & -1.49 \\
& 15 & 22.0 & 3.85 & 0.331 & 0.097 & 1.08 & 0.27 \\
& 17 & 11.1 & -1.39 & 0.659 & 0.906 & 0.67 & 0.37 \\
& 21 & 14.0 & -5.30 & 0.801 & 0.953 & 0.45 & 0.29 \\
& 22 & 21.7 & -5.08 & 0.914 & 0.230 & 0.43 & 0.33 \\
& 23 & 12.1 & -1.76 & 0.895 & 0.977 & 0.32 & -0.47 \\
& 31 & 24.1 & 0.81 & 0.121 & 0.038 & 1.48 & 0.89 \\
& 41 & 21.4 & -3.86 & 0.149 & 0.156 & 0.80 & 1.95 \\
& 42 & 9.0 & -3.32 & 0.872 & 0.935 & 0.45 & -0.27 \\
& 44 & 13.1 & -1.12 & 0.322 & 0.466 & 0.62 & 1.40 \\
& 51 & 25.6 & -1.04 & 0.867 & 0.368 & 0.90 & 0.41 \\
& 52 & 14.0 & 1.80 & 0.112 & 0.223 & 0.95 & 0.07 \\
& 53 & 14.4 & -2.30 & 0.384 & 0.643 & 0.61 & 0.11 \\
& 61 & 14.2 & 5.27 & 0.067 & 0.068 & 1.28 & 1.30 \\
& 64 & 15.3 & 0.27 & 0.300 & 0.465 & 0.94 & 1.33 \\
\hline
\end{tabular}

Table 14. Test for isotropy of the orientations of the galaxy plane. The distribution of the angle $\eta$ of galaxies, SP galaxies, inclination was obtained according to HHD and PP corrections. 
SOME ASPECTS OF THE ORIENTATION OF GALAXIES IN CLUSTERS

\begin{tabular}{|c|c|c|c|c|c|c|c|}
\hline angle & group & $\chi^{2}$ & $C$ & $P\left(\Delta_{1}\right)$ & $P(\Delta)$ & $\lambda$ & $\Delta_{11} / \sigma\left(\Delta_{11}\right)$ \\
\hline \multirow{18}{*}{$\eta$} & 11 & 29.3 & 14.70 & 0.000 & 0.000 & 1.27 & 4.09 \\
\hline & 12 & 10.3 & -1.23 & 0.509 & 0.794 & 0.40 & -0.96 \\
\hline & 13 & 14.5 & -4.23 & 0.617 & 0.635 & 0.60 & 0.80 \\
\hline & 14 & 32.0 & 10.08 & 0.004 & 0.002 & 1.40 & 2.09 \\
\hline & 15 & 16.0 & -3.50 & 0.808 & 0.915 & 0.67 & -0.18 \\
\hline & 17 & 17.9 & 7.82 & 0.091 & 0.123 & 1.24 & -0.64 \\
\hline & 21 & 14.6 & -4.47 & 0.808 & 0.632 & 0.59 & -0.53 \\
\hline & 22 & 12.7 & -2.57 & 0.986 & 0.988 & 0.46 & -0.15 \\
\hline & 23 & 12.8 & -0.38 & 0.301 & 0.630 & 0.50 & -0.894 \\
\hline & 31 & 14.5 & 2.69 & 0.167 & 0.237 & 1.20 & 0.99 \\
\hline & 41 & 21.3 & 1.91 & 0.052 & 0.124 & 1.11 & 1.79 \\
\hline & 42 & 36.5 & 16.64 & 0.009 & 0.000 & 1.89 & 0.26 \\
\hline & 44 & 15.7 & 4.14 & 0.479 & 0.101 & 0.82 & -1.21 \\
\hline & 51 & 19.9 & 1.88 & 0.098 & 0.197 & 1.05 & 2.06 \\
\hline & 52 & 21.5 & 6.32 & 0.030 & 0.050 & 1.42 & 2.05 \\
\hline & 53 & 12.5 & -3.00 & 0.921 & 0.953 & 0.49 & 0.03 \\
\hline & 61 & 14.4 & -1.80 & 0.139 & 0.412 & 0.77 & 0.37 \\
\hline & 64 & 27.0 & -6.00 & 0.458 & 0.692 & 0.67 & 1.24 \\
\hline
\end{tabular}

Table 15. Test for isotropy of the orientations of the galaxy plane. The distribution of the angle $\eta$ of galaxies, NSP galaxies, inclination was obtained according to HHD and PP corrections.

\begin{tabular}{|c|c|c|c|c|c|c|c|}
\hline angle & group & $\chi^{2}$ & $C$ & $P\left(\Delta_{1}\right)$ & $P(\Delta)$ & $\lambda$ & $\Delta_{11} / \sigma\left(\Delta_{11}\right)$ \\
\hline \multirow{18}{*}{$P$} & 11 & 17.7 & -9.32 & 0.991 & 0.910 & 0.40 & -0.01 \\
\hline & 12 & 19.5 & 0.19 & 0.113 & 0.137 & 0.99 & -0.49 \\
\hline & 13 & 16.7 & 1.40 & 0.805 & 0.245 & 0.81 & -0.63 \\
\hline & 14 & 14.2 & 2.21 & 0.943 & 0.196 & 0.44 & -0.34 \\
\hline & 15 & 12.0 & -0.86 & 0.201 & 0.381 & 1.03 & 0.26 \\
\hline & 17 & 10.7 & -5.57 & 0.656 & 0.715 & 0.58 & -0.78 \\
\hline & 21 & 11.2 & -3.53 & 0.859 & 0.939 & 0.55 & -0.36 \\
\hline & 22 & 15.1 & -1.49 & 0.997 & 0.999 & 0.57 & -0.01 \\
\hline & 23 & 12.3 & 0.27 & 0.230 & 0.453 & 0.81 & -1.37 \\
\hline & 31 & 23.3 & 4.07 & 0.444 & 0.052 & 0.83 & 0.43 \\
\hline & 41 & 21.3 & 9.17 & 0.481 & 0.011 & 1.08 & -0.58 \\
\hline & 42 & 18.1 & 2.38 & 0.075 & 0.172 & 1.04 & -1.59 \\
\hline & 44 & 19.3 & -2.14 & 0.352 & 0.694 & 0.84 & 0.79 \\
\hline & 51 & 21.0 & 0.00 & 0.759 & 0.069 & 0.82 & -0.60 \\
\hline & 52 & 8.5 & -1.63 & 0.788 & 0.878 & 0.37 & 0.68 \\
\hline & 53 & 16.3 & 0.86 & 0.135 & 0.281 & 1.24 & 1.32 \\
\hline & 61 & 27.7 & 1.38 & 0.040 & 0.011 & 1.47 & -0.54 \\
\hline & 64 & 17.5 & 3.08 & 0.331 & 0.519 & 1.14 & -1.28 \\
\hline
\end{tabular}

Table 16. Test for isotropy of the orientations of the galaxy plane. The distribution of the angle $P$ of galaxies. Only galaxies with certain measure $P$ are taken into account. 
P. PAJOWSKA, W. GODŁOWSKI, E. PANKO, P. FLIN

\begin{tabular}{|c|c|c|c|c|c|c|c|}
\hline angle & group & $\chi^{2}$ & $C$ & $P\left(\Delta_{1}\right)$ & $P(\Delta)$ & $\lambda$ & $\Delta_{11} / \sigma\left(\Delta_{11}\right)$ \\
\hline \multirow{6}{*}{} & 11 & 20.1 & -8.40 & 0.570 & 0.772 & 0.52 & -0.58 \\
& 12 & 16.6 & -0.92 & 0.166 & 0.345 & 0.87 & -0.54 \\
& 13 & 15.6 & 4.80 & 0.430 & 0.073 & 0.79 & -1.21 \\
& 14 & 15.6 & 4.53 & 0.406 & 0.199 & 0.67 & -0.54 \\
& 15 & 14.0 & -2.50 & 0.275 & 0.482 & 1.00 & -0.39 \\
& 17 & 11.7 & -5.00 & 0.702 & 0.733 & 0.62 & 0.00 \\
& 21 & 21.4 & -8.66 & 0.657 & 0.662 & 0.88 & -0.82 \\
& 22 & 13.8 & -1.09 & 0.847 & 0.987 & 0.67 & -0.36 \\
& 23 & 12.8 & 1.69 & 0.272 & 0.270 & 0.78 & -0.74 \\
& 31 & 18.2 & -1.39 & 0.266 & 0.169 & 0.74 & -0.45 \\
& 41 & 20.0 & 8.35 & 0.850 & 0.012 & 0.74 & -0.10 \\
& 42 & 14.6 & 1.34 & 0.149 & 0.236 & 0.89 & -0.91 \\
& 44 & 16.0 & -3.00 & 0.371 & 0.700 & 0.71 & 0.46 \\
& 51 & 21.0 & -1.50 & 0.817 & 0.075 & 0.82 & -0.48 \\
& 52 & 7.6 & 0.17 & 0.376 & 0.673 & 0.55 & 1.32 \\
& 53 & 17.0 & -4.94 & 0.511 & 0.719 & 0.76 & 0.61 \\
& 61 & 22.4 & -2.18 & 0.133 & 0.078 & 1.11 & -0.23 \\
& 64 & 16.0 & 3.00 & 0.506 & 0.369 & 1.18 & -0.69 \\
\hline
\end{tabular}

Table 17. Test for isotropy of the orientations of the galaxy plane. The distribution of the angle $P$ of galaxies, SP galaxies. Only galaxies with a certain measure of $P$ are taken into account.

\begin{tabular}{|c|c|c|c|c|c|c|c|}
\hline angle & group & $\chi^{2}$ & $C$ & $P\left(\Delta_{1}\right)$ & $P(\Delta)$ & $\lambda$ & $\Delta_{11} / \sigma\left(\Delta_{11}\right)$ \\
\hline \multirow{6}{*}{} & 11 & 15.3 & 5.96 & 0.101 & 0.158 & 0.85 & 1.32 \\
& 12 & 14.0 & 1.00 & 0.664 & 0.408 & 0.47 & 0.00 \\
& 13 & 11.6 & -1.00 & 0.640 & 0.889 & 0.74 & 0.83 \\
& 14 & 17.4 & -2.17 & 0.350 & 0.369 & 0.82 & 0.12 \\
& 15 & 12.0 & 3.00 & 0.180 & 0.167 & 0.95 & 1.64 \\
& 17 & 11.0 & -1.86 & 0.374 & 0.665 & 0.59 & -1.35 \\
& 21 & 16.0 & -7.00 & 0.759 & 0.734 & 0.71 & 0.73 \\
& 22 & 19.4 & -1.14 & 0.818 & 0.951 & 0.59 & 0.44 \\
& 23 & 26.4 & -7.00 & 0.269 & 0.379 & 0.65 & -1.54 \\
& 31 & 30.0 & 6.00 & 0.171 & 0.045 & 1.44 & 1.83 \\
& 41 & 9.0 & 1.50 & 0.330 & 0.436 & 0.96 & -0.97 \\
& 42 & 16.8 & 2.09 & 0.178 & 0.331 & 0.80 & -1.85 \\
& 44 & 15.0 & 3.00 & 0.613 & 0.262 & 0.96 & 0.99 \\
& 51 & 9.0 & 0.00 & 0.916 & 0.924 & 0.38 & -0.40 \\
& 52 & 27.0 & -3.00 & 0.097 & 0.155 & 0.87 & -1.22 \\
& 53 & 14.2 & 1.60 & 0.115 & 0.319 & 1.17 & 1.60 \\
& 61 & 18.0 & 4.50 & 0.180 & 0.167 & 1.15 & -0.83 \\
& 64 & 16.1 & -1.86 & 0.422 & 0.648 & 0.50 & -1.31 \\
\hline
\end{tabular}

Table 18. Test for isotropy of the orientations of the galaxy plane. The distribution of the angle $P$ of galaxies, NSP galaxies. Only galaxies with a certain measure of $P$ are taken into account. 
Returning to the analysis of samples $A$ divided according to the morphological type we do not find any alignment for spiral $(S P)$ galaxies while for a sample of non-spiral $(N S P)$ galaxies we found non randomness in the distributions of $\delta_{D}$ and $\eta$ angles for the fifth and seventh groups, respectively. During the analysis of sample B we observed the disappearience of the alignment. For position angles $P$ we do not observe any alignment. During the analysis the $\delta_{D}$ angle for spiral galaxies we observed an alignment for group 53 while for the nonspiral we observed an alignment for groups 11 and 51. In the case of the $\eta$ angle the non randomness was observed in two groups for All galaxies (groups 11 and 41) and in four groups (11, 14, 42 and 52) for non-spiral galaxies. It confirms Godłowski's [4] conclusion that any possibly observed alignment for the galaxies in sample $A$ is caused by the reason of the wrong assumption the "true" axial ratio especially for non-spiral galaxies.

For a more detailed analysis we used the method described in [3]. Our question is, whether we could say that we found an alignment in the whole analyzed sample of 18 Tully's groups of galaxies or not. So we computed the mean value and the variance of analyzed statistics: $\chi^{2}$, $\Delta_{1} / \sigma\left(\Delta_{1}\right), \Delta / \sigma(\Delta)$ (i.e., the same statistics were analyzed in [2]) for our sample of 18 groups and compared them with the results of numerical simulations. We performed 1000 simulations of 18 fictious clusters, each with a number of randomly oriented, galaxy's members, the same as in real clusters separately for All (see [4]), for spiral, and for non-spiral galaxies. In Table 19 we presented average values of the analyzed statistics, their standard deviations, standard deviations in the sample as well as their standard deviations for the distribution of $P$ angles obtained from numerical simulations. One should note that there are some differences in the results of numerical simulations for $P, \delta_{D}$ and $\eta$ angles but it does not change our further conclusions.

The mean values and variance of the analyzed statistics for a sample of real clusters were presented in Table 20. It shows that (for sample A) the analysis of the position angles for All and spiral galaxies does not show a significant deviation from the values expected in the case of random distributions, while marginal effect is observed for non-spiral galaxies. The analysis of $\delta_{D}$ and $\eta$ angles shows the existence of alignment at the $2 \sigma$ level (with the exception of $\Delta / \sigma(\Delta)$ statistics for the $\delta_{D}$ angle) for a subsample of All galaxies and even a stronger effect for non-spiral galaxies. The spiral galaxies do not show this effect. For sample $B$ generally we do not observe a deviation from the values expected in the case of random distributions. The above results allowed us to conclude that we did not observe any significant alignment for Tully's groups of galaxies.

\section{DISCUSSION AND CONCLUSIONS}

In the present paper the investigation of the orientation of galaxies inside 18 Tully's groups of galaxies belonging to the Local Supercluster divided according to morphological type was performed. We do not find any significant alignment in the orientation of galaxies in the analyzed groups of galaxies. As a result we concluded that the orientations of galaxies in the Tully's groups are random the presence of a possible weak alignment for spiral galaxies calls for investigations in the future. We also analyzed the observational effect generated by the process of deprojection of galaxies found by Godłowski and Ostrowski [36], which masks substantially any possible alignment during the analysis of the spatial orientation of galaxies in clusters. We confirmed Godłowski's suggestion $[4,14]$ that this effect is contributed to the wrong aproximation of the "true shape" of galaxies, especialy for non-spiral galaxies. We have shown that using the "true shape" of galaxies $q_{0}$ depending on the morphological type according to Heidmann et al. [37] with the help of Fouque \& Paturel [38] corrections of $q$ to standard photometrical axial ratios allowed us to avoid this problem. This gives a much more powerful investigation of the spatial orientation of galaxies.

Our results, lack of the alignment for less masive galaxies structures together with results of our previous papers $[3,14,30,31,44]$, confirm our suggestion that the alignment of galaxies increases with the mass of the structures $[14,15]$. A similar result was also obtained by Aryal et al. [16] based on the series of their papers [56-58]. In our opinion the observed relation between the richness of the galaxy cluster and the alignment is due to the tidal torque, as suggested by [59], however, it is also in agreement with prediction of the Li model [60] in which galaxies form in the rotating universe.

It should be noticed that Gonzalez and Teodoro [29] interpreted the the alignment of just the brightest galaxies within a cluster as an effect of action of gravitational tidal forces. Recently, there have been also some attempts to investigate the galaxy angular momenta on a large scale. Paz, Stasyszyn and Padilla [61] analysing galaxies from the Sloan Digital Sky Survey catalogue found that the galaxy angular momenta are aligned perpendicularly to the planes of large-scale structures where as there is no such effect for the low-mass structures. They interpret this as consistent with their simulations based on the mechanism of tidal interactions. Jones, van der Waygaert and Aragon-Calvo [62] found that the spins of spiral galaxies located within cosmic web filaments tend to be aligned along the larger axis of the filament, which they interpreted as "fossil" evidence indicating that the action of large scale tidal torques effected the alignments of galaxies located in cosmic filaments.

In the commonly accepted $\Lambda \mathrm{CDM}$ model, the Universe deems to be spatially flat as well as homogeneous and isotropic at the appropriate scale. In this model the structure was formed from the primordial adiabatic, nearly scale invariant Gaussian random fluctuations [63-65]. This picture is in agreement with both the numerous numerical simulations [66-69] and the observations.

Usually, the dependence between the angular momentum and the mass of the structure is presented as the empirical relation $J \sim M^{5 / 3}[61,70-74]$, for the review 
see also [75]. In our opinion, it is due to the tidal torque, as suggested by $[59,76]$. Also $[77,78]$ analysing the linear tidal torque theory noticed the connection of the alignment with the considered scale of structure. However, other possibilities, as Li model [60], for example, are also not excluded.

\begin{tabular}{|c|c|c|c|c|c|}
\hline Sample & Test & $\bar{x}$ & $\sigma(x)$ & $\sigma(\bar{x})$ & $\sigma(\sigma(x))$ \\
\hline \multirow{3}{*}{ All } & $\chi^{2}$ & 16.9524 & 1.4592 & 0.0461 & 0.0326 \\
& $\Delta_{1} / \sigma\left(\Delta_{1}\right)$ & 1.2513 & 0.1543 & 0.0048 & 0.0034 \\
& $\Delta / \sigma(\Delta)$ & 1.8772 & 0.1581 & 0.0050 & 0.0035 \\
\hline \multirow{3}{*}{$\mathrm{SP}$} & $\chi^{2}$ & 17.0283 & 1.3628 & 0.0431 & 0.0305 \\
& $\Delta_{1} / \sigma\left(\Delta_{1}\right)$ & 1.2552 & 0.1544 & 0.0049 & 0.0035 \\
& $\Delta / \sigma(\Delta)$ & 1.8827 & 0.1543 & 0.0049 & 0.0035 \\
\hline \multirow{2}{*}{$\mathrm{NSP}$} & $\chi_{1}^{2}$ & 17.1042 & 1.3485 & 0.0426 & 0.0302 \\
& $\Delta_{1} / \sigma\left(\Delta_{1}\right)$ & 1.2607 & 0.1541 & 0.0049 & 0.0034 \\
& $\Delta / \sigma(\Delta)$ & 1.8900 & 0.1595 & 0.0050 & 0.0036 \\
\hline
\end{tabular}

Table 19. The results of numerical simulations for positions angles $P$.

\begin{tabular}{|c|c|c|c|c|c|c|c|}
\hline & & $P$ & & $\delta_{I}$ & & $\eta$ & \\
\hline Sample & Test & $\bar{x}$ & $\sigma(x)$ & $\bar{x}$ & $\sigma(x)$ & $\bar{x}$ & $\sigma(x)$ \\
\hline & $\chi^{2}$ & 17.34 & 1.06 & 23.79 & 2.85 & 26.58 & 2.95 \\
\hline$A_{\text {all }}$ & $\Delta_{1} / \sigma\left(\Delta_{1}\right)$ & 1.28 & 0.18 & 1.85 & 0.26 & 2.44 & 0.29 \\
\hline & $\Delta / \sigma(\Delta)$ & 2.11 & 0.21 & 2.33 & 0.26 & 2.91 & 0.27 \\
\hline & $\chi^{2}$ & 16.61 & 0.91 & 18.93 & 1.18 & 19.95 & 1.65 \\
\hline$A_{\mathrm{sp}}$ & $\Delta_{1} / \sigma\left(\Delta_{1}\right)$ & 1.26 & 0.12 & 1.31 & 0.16 & 1.53 & 0.16 \\
\hline & $\Delta / \sigma(\Delta)$ & 2.13 & 0.18 & 1.98 & 0.14 & 2.18 & 0.17 \\
\hline & $\chi^{2}$ & 19.10 & 1.16 & 27.79 & 4.16 & 27.03 & 3.61 \\
\hline$A_{\mathrm{nsp}}$ & $\Delta_{1} / \sigma\left(\Delta_{1}\right)$ & 1.45 & 0.15 & 2.45 & 0.27 & 2.78 & 0.33 \\
\hline & $\Delta / \sigma(\Delta)$ & 1.97 & 0.17 & 2.87 & 0.28 & 3.27 & 0.33 \\
\hline & $\chi^{2}$ & 16.80 & 1.15 & 18.70 & 1.33 & 20.19 & 2.17 \\
\hline$B_{\text {all }}$ & $\Delta_{1} / \sigma\left(\Delta_{1}\right)$ & 1.22 & 0.18 & 1.42 & 0.17 & 1.55 & 0.23 \\
\hline & $\Delta / \sigma(\Delta)$ & 2.08 & 0.22 & 2.08 & 0.17 & 2.39 & 0.30 \\
\hline & $\chi^{2}$ & 16.36 & 0.89 & 18.24 & 1.13 & 17.68 & 1.25 \\
\hline$B_{\mathrm{sp}}$ & $\Delta_{1} / \sigma\left(\Delta_{1}\right)$ & 1.28 & 0.11 & 1.26 & 0.21 & 1.28 & 0.15 \\
\hline & $\Delta / \sigma(\Delta)$ & 2.07 & 0.18 & 2.15 & 0.16 & 2.12 & 0.20 \\
\hline & $\chi^{2}$ & 16.56 & 1.41 & 15.57 & 1.37 & 19.07 & 1.77 \\
\hline$B_{\mathrm{nsp}}$ & $\Delta_{1} / \sigma\left(\Delta_{1}\right)$ & 1.43 & 0.12 & 1.38 & 0.20 & 1.78 & 0.26 \\
\hline & $\Delta / \sigma(\Delta)$ & 1.97 & 0.15 & 1.94 & 0.20 & 2.19 & 0.28 \\
\hline
\end{tabular}

Table 20. The statistics of the observed distributions for real clusters.
[1] D. I. Hawley, P. J. E. Peebles, Astron. J. 80, 477 (1975).

[2] W. Godłowski, P. Piwowarska, E. Panko, P. Flin, Astron. J. 723, 985 (2010).

[3] W. Godłowski, Astrophys. J. 747, 7 (2012).

[4] W. Godłowski, Acta Phys. Polon. B 42, 2323 (2011).

[5] P. J. E. Peebles, Astron. J. 155, 393 (1969).

[6] B. Ya. Zeldovich, Astron. Astrophys. 5, 84 (1970).

[7] A. R. Sunyaev, Ya. B. Zeldovich, Astron. Astrophys. 20, 189 (1972).

[8] A. G. Doroshkevich, Astrophys. Lett. 14, 11 (1973).

[9] S. F. Shandarin, Sov. Astron. 18, 392 (1974).

[10] P. S. Wesson, Vistas Astron. 26, 225 (1982).

[11] J. Silk, G. A. Efstathiou, Fund. Cosm. Phys. 9, 1 (1983).

[12] A. Dekel, Astron. J. 298, 461 (1985).

[13] R. G. Bower et al., Mon. Not. R. Astron. Soc. 370, 645 (2006).

[14] W. Godłowski, Int. J. Mod. Phys. D 20, 1643 (2011).

[15] W. Godłowski, M. Szydłowski, P. Flin, Gen. Rel. Grav. 37, 615 (2005).

[16] B. Aryal, S. Paudel, W. Saurer, Mon. Not. R. Astron. Soc. 379, 1011 (2007).

[17] H. S. Hwang, M. G. Lee, Astrophys. J. 662, 236 (2007).

[18] L. A. Thompson, Astrophys. J. 209, 22 (1976).

[19] M. T. Adams, K. M. Strom, S. E. Strom, Astrophys. J. 238, 445 (1980).

[20] G. Helou, E. E. Salpeter, Astrophys. J. 252, 75 (1982).

[21] H. T. MacGillivray, R. J. Dodd, in ESO Workshop on the Virgo Cluster, ESO, edited by B. Binggeli Garching bei Munchen (1985), p. 217.

[22] F. A. Bukhari, Astrophys. J., 333, 564 (1988).

[23] F. A. Bukhari, L. E. Cram, Astrophys. Space Sci. 283,
169 (2003).

[24] C. Han, A. Gould, P. Sackett, Astrophys. J. 445, 46 (1995).

[25] P. Flin, R. P. Olowin, in Physical Cosmology, edited by A. Blanchard, L. Celniker, M. Lachieze-Rey, Tran Thanh Van, (Editions Frontiére, Gif-sur-Yvette, Cedex-France, 1991), p. 512.

[26] D. Trevese, G. Cirimele, P. Flin, Astron. J. 104, 935 (1992).

[27] R. Kim, in American Astronomical Society, 199 AAS Meeting, Bull. Am. Astron. Soc. 33, 1521 (2001).

[28] L. Torlina, R. De Propris, M. J. West, Astrophys. J. 660, L97 (2007).

[29] A. Gonzalez-Sanchez, L. Teodoro, Mon. Not. R. Astron. Soc. 404, L11 (2010).

[30] W. Godłowski, F. W. Baier, H. T. MacGillivray, Astron. Astrophys. 339, 709 (1998).

[31] F. W. Baier, W. Godłowski, H. T. MacGillivray, Astron. Astrophys. 403, 847 (2003).

[32] S. Djorgovski, Astrophys. J. 274, L11 (1983).

[33] M. G. Kitzbichler, W. Saurer, Astrophys. J. 590, L9 (2003).

[34] G. X. Wu, F. X. Hu, H. J. Su, Y. Z. Liu, Chin. Astron. Astrophys. 22, 17 (1998)

[35] R. B. Tully, Nearby Galaxy Catalog (Cambridge, 1988).

[36] W. Godłowski, M. Ostrowski, Mon. Not. R. Astron. Soc. 303, 50 (1999).

[37] J. Heidmann, N. Heidmann, G. de Vaucouleurs, Mon. Not. R. Astron. Soc. 75, 85 (1972).

[38] P. Fouque, G. Paturel, Astron. Astrophys. 150, 192 (1985). 
[39] R. B. Tully, Astrophys. J. 321, 280 (1987).

[40] P. Nilson, Uppsala General Catalogue of Galaxies, Astr. Obs. Ann. V. Vol.1 (Uppsala, 1973).

[41] P. Nilson, Catalogue of Selected Non-UGC Galaxies, Uppsala Astr. Obs. Rep. 5 (Uppsala, 1974).

[42] A. Labuerts, ESO/UppsalaSurvey of the ESO B Atlas (ESO, Garching, 1982).

[43] A. Lauberts, E. Valentijn, The Surface Photometry Catalogue of the ESO-Uppsala Galaxies (ESO, Garching, 1989).

[44] W. Godłowski, P. Flin, Astrophys. J. 708, 902 (2010).

[45] R. B. Tully, E. J. Shaya, Astrophys. J. 281, 31 (1984).

[46] E. J. Öpik, Irish Astron. J. 9, 211 (1970).

[47] J. Jaaniste, E. Saar, in The large scale structures of the Universe. IAU Symp. 79, edited by M. S. Longair, J. Einasto (D. Reidel, Dordrecht, 1978), p. 448

[48] P. Flin, W. Godłowski, Mon. Not. R. Astron. Soc. 222, 525 (1986).

[49] P. Flin, W. Godłowski, Sov. Astron. Lett. 15, 374 (1989); Pisma Astron. Zurn. 15, 867 (1989).

[50] P. Flin, W. Godłowski, Sov. Astron. Lett. 65, 209 (1990); Pisma Astron. Zurn. 16, 490 (1990).

[51] W. Godłowski, Mon. Not. R. Astron. Soc. 265, 874 (1993).

[52] W. Godłowski, Mon. Not. R. Astron. Soc. 271, 19 (1994).

[53] B. Aryal, W. Saurer, Astron. Astrophys. 364, L97 (2000).

[54] E. Holmberg, Medd. Lund. Astron. Obs. Ser. VI, No 117 (1946).

[55] G. A. Tammann, A. Sandage, Astrophys. J. 207, L1 (1976).

[56] B. Aryal, W. Saurer, Astron. Astrophys. 425, 871 (2004).

[57] B. Aryal, W. Saurer, Astron. Astrophys. 432, 431 (2005).

[58] B. Aryal, W. Saurer, Mon. Not. R. Astron. Soc. 336, 438 (2006).
[59] P. Catelan, T. Theuns, Mon. Not. R. Astron. Soc. 282, 436 (1996).

[60] Li. Li-Xin, Gen. Rel. Grav 30, 497 (1998).

[61] D. J. Paz, F. Stasyszyn, N. D. Padilla, Mon. Not. R. Astron. Soc. 389, 1127 (2008).

[62] B. Jones, R. van der Waygaert, M. Aragon-Calvo, Mon. Not. R. Astron. Soc. 408, 897 (2010).

[63] J. Silk, Astrophys. J. 151, 459 (1968).

[64] P. J. E. Peebles, J. T. Yu, Astrophys. J. 162, 815 (1970).

[65] A. R. Sunyaev, Ya. B. Zeldovich, Astrophys. Space Sci. 7, 3 (1970).

[66] V. Springel et al., Nature 435, 629 (2005).

[67] R. van de Weygaert, J. R. Bond, in A Pan-Chromatic View of Clusters of Galaxies and the Large-Scale Structures, edited by M. Plionis, O. Lopez-Cruz, D. Hughes (Springer, Dordrecht, 2008), p. 335.

[68] R. van de Weygaert, J. R. Bond, in A Pan-Chromatic View of Clusters of Galaxies and the Large-Scale Structures, edited by M. Plionis, O. Lopez-Cruz, D. Hughes (Springer, Dordrecht, 2008), p. 409.

[69] S. Codis et al., Mon. Not. R. Astron. Soc. 427, 3320 (2012).

[70] P. S. Wesson, Astron. Astrophys. 80, 269 (1979).

[71] P. S. Wesson, Astron. Astrophys. 119, 313 (1983).

[72] L. Carrasco, M. Roth, A. Serrano, Astron. Astrophys. 106, 89 (1982).

[73] Brosche, P. 1986, Comm. Astrophys., 11, 213

[74] A. J. Romanowsky, S. M. Fall, preprint arXiv:1207.4189 (2012).

[75] B. M. Schäfer, Int. J. Mod. Phys. D 18, 173 (2009).

[76] A. Heavens, J. Peacock, Mon. Not. R. Astron. Soc. 232, 339 (1988).

[77] Y. Noh, J. Lee, preprint astro-ph/0602575 (2006).

[78] Y. Noh, J. Lee, Astrophys. J. 652, L71 (2006).

\title{
ДЕЯКІ АСПЕКТИ ОРІЕНТАЦІЇ ГАЛАКТИК У СКУПЧЕННЯХ
}

\author{
П. Пайовска ${ }^{1}$, В. Годловскі ${ }^{2}$, О. Панько ${ }^{3}$, П. Флін ${ }^{4}$ \\ ${ }^{1}$ Інститут фізики Опольсъкого університету, вул. Олесъка, 48, 45-052, Ополе, Польща \\ ${ }^{2}$ Інститут фізики Опольсъкого університету, вул. Олесъка, 48, 45-052, Ополе, Полъща \\ ${ }^{3}$ Астрономічна обсерваторія імені Каліненкова, Миколаӥвський національний університет, \\ Нікольсъка, 24, 54030, Миколаїв, Україна \\ ${ }^{4}$ Інститут фізики Університету імені Яна Кохановсъкого, \\ вул. Свєнтокшиска, 15, 25-406, Кельще, Польща
}

Проаналізовано орієнтації груп галактик Таллі, що належать до Місцевого Надскупчення. У 1975 році Гоулі та Піблз [D. I. Hawley, P. J. E. Peebles, Astron. J. 80, 477 (1975)] представили метод досліджень орієнтації галактик у великих структурах. У наших попередніх статтях [W. Godłowski, P. Piwowarska, E. Panko, P. Flin, Astron. J. 723, 985 (2010); W. Godłowski, Astrophys. J. 747, 7 (2012)] докладно проаналізовано й дещо удосконалено статистичний тест дослідження невипадкових орієнтацій галактик Гоулі та Піблза, на основі чого запропоновано новий метод аналізу вирівнювання галактик у скупченнях.

Використовуючи його, Годловскі [W. Godłowski, Acta Phys. Polon. В 42, 2323 (2011)] проаналізував орієнтацію галактик у групах Таллі та не знайшов суттєвого відхилення від ізотропії як позиційних кутів, так і кутів $\delta_{D}$ і $\eta$, що визначають орієнтації площин галактик. У статті ми докладно та методично дослідили залежність вирівнювання орієнтації галактик, що належать до груп Таллі, від морфологічного типу галактик. Крім того, ми аналізуємо наслідки різних припущень щодо “справжньої форми” галактик різних морфологічних типів та можливий вплив цієї проблеми на вивчення просторової орієнтації галактик. Також ми обговорюємо застосування отриманих результатів у теорї формування галактик. 